\title{
The pattern of surface deformations in the Dabrowa Basin (Poland) based on PSInSAR analysis
}

\author{
Andrzej LEŚNIAK ${ }^{1}$ and Stanisława PORZYCKA-STRZELCZYK ${ }^{1, *}$ \\ 1 AGH University of Science and Technology, al. A. Mickiewicza 30, 30-059 Kraków, Poland
}

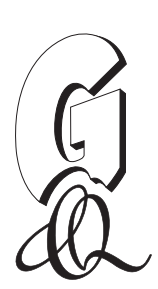

Leśniak, A., Porzycka-Strzelczyk, S., 2020. The pattern of surface deformations in the Dąbrowa Basin (Poland) based on PSInSAR analysis. Geological Quarterly, 64 (2): 304-318, doi: 10.7306/gq.1537

Associate Editor: Tomisław Gołębiowski

Slow, long-term ground deformations in the Dabrowa Basin (southern Poland) were identified based on ERS-1, ERS-2 and ENVISAT Synthetic Aperture Radar (SAR) images that were processed by means of Permanent Scatterer SAR Interferometry (PSInSAR). The Dąbrowa Basin is a region where two major factors can affect surface stability: intensive coal exploitation and neotectonic processes. In this study, in order to clarify the origin of surface deformations, the authors propose applying a newly developed algorithm of spatio-temporal PSInSAR data analysis. This analysis revealed that subsidence is a characteristic feature of the Dabrowa Basin. A significant correlation exists between slow, long-term ground deformations and the location of the main tectonic structure of this region. The proposed spatiotemporal analysis of the PSInSAR data additionally showed some degree of correlation between mining activity and the studied deformations. This interconnection is a significant achievement of this study since the deformation values determined by means of PSInSAR were identified in earlier works solely on the basis of Dąbrowa Basin neotectonics.

Key words: PSInSAR, coal exploitation, neotectonics, ground deformation, geostatistics.

\section{INTRODUCTION}

The Dabrowa Basin is a region in southern Poland with a very complex tectonic structure and a long history of coal exploitation. Both of the factors make this area particularly vulnerable to ground deformation. Different types of surface deformation have been identified in the Dabrowa Basin - both continuous and discontinuous. Besides rapid and intense deformations related directly to mining exploitation, slow (ca. several $\mathrm{mm} /$ year), long-term vertical ground movements have also been observed. They were identified based on satellite radar images processed with Permanent Scatterer SAR Interferometry (PSInSAR). This method makes use of a set of satellite radar images in order to detect small long-term ground deformations (Ferretti et al., 2000, 2001). Our preliminary analysis of PSInSAR data revealed a significant correlation between the tectonic structure of the Dabrowa Basin and ground deformation values (Graniczny et al., 2008; Leśniak and Porzycka, 2009b). Such a result seems to confirm research conducted on neotectonic movements in this region. Besides the confirmed

\footnotetext{
* Corresponding author, e-mail: porzycka@agh.edu.pl Received: January 9, 2019; accepted: 20 February, 2020; first published online: May 29, 2020
}

correlation between ground deformations and tectonic structure, it is also vital to take into account the impact of intensive coal exploitation in the Dabrowa Basin. One issue that requires addressing is whether the observed surface movement values also correlate with mining activity. To perform this task, the authors proposed a specially developed algorithm - spatio-temporal PSInSAR data analysis. This tool can help determine the origin of ground deformation in regions where many factors can affect surface stability.

In the present study, surface deformation patterns in the Dabrowa Basin were analysed on the basis of PSInSAR data. The timeframe of the analysis was 1992-2003. The obtained results were analysed both for the Dabrowa Basin as a whole and separately for the mining area covered by the "Grodziec" coal mine.

\section{DAZBROWA BASIN AND "GRODZIEC" COAL MINE}

The region analysed in the present study, i.e. the Dabrowa Basin, is located in southern Poland and is a part of the Upper Silesian Coal Basin (USCB). This highly industrialized region covers an area of $\sim 150 \mathrm{~km}^{2}$. A large part of this region is highly urbanized and densely populated. The Dabrowa Basin is susceptible to various types of ground deformation, both natural and anthropogenic. 


\section{TECTONIC SETTINGS}

The Dabrowa Basin, as well as the entire Upper Silesian Coal Basin, has a complex tectonic structure. Its major system of faults, folds and troughs took shape during the Variscan Orogeny (the Asturian phase; Trzepierczyński et al., 1985). The research area is located within a disjunctive tectonic zone. A characteristic feature of this region is the occurrence of SW-NE-trending structural units. Many faults are also located here (Fig. 1), most of which are normal faults with a hade as steep as $70^{\circ}$. The main fault zone in this area is the Będziński Fault dating back to the Late Miocene sub-epoch. The Będziński Fault trends NW-SE. The fault throw values gradually shift from 200 to $50 \mathrm{~m}$ in this direction. Its southern wing is thrown down. The Będziński Fault is intersected by many faults running approximately meridionally. The throws of these faults vary from several tens of metres to $>300 \mathrm{~m}$. The Alpine fault system in the studied region is mainly secondary and it follows the orientation of the Carboniferous faults.

The Carboniferous deposits of the study area, i.e. the Dabrowa Basin, are highly diverse in terms of both lithology and facies. They are also characterized by a varying thickness. This area features three lithostratigraphic series: a paralic series (Namurian A), an Upper Silesian sandstone series (Namurian B and $C$ ), and a mudstone series (Westphalian $A$ and $B$ ). A sketch of the range of productive Carboniferous coal-bearing rocks in the analysed area is shown in Figure 2. The paralic series is distinguished by the presence of coal seams and marine and coal-deficient deposits. The series is composed of conglomerates, sandstones, claystones, siltstones, coal shale and coals. The Upper Silesian sandstone series marks the beginning of the sedimentation of carbonaceous deposits of the Upper Silesian Coal Basin and consists mainly of sandstones and conglomerates, as well as thick coal seams. Within this series, two lithostratigraphic members can be distinguished: Saddle Beds and Ruda Beds layers. It is in the saddle layers that the thickest coal seams are found. The Ruda Beds with a thickness of up to $24 \mathrm{~m}$ in the study area, are a characteristic feature of them. On the other hand, the Upper Silesian sandstone series features no levels with marine fauna, which occur in the paralic series. Overlying series is the mudstone series. It is divided into two lithostratigraphic units: the Załęże and Orzesze units, and made up primarily of small-scale deposits (mainly mudstones). Coal layers are very numerous but thin, often overgrown with gangue.

The "Grodziec" coal mine is located on the northern side of the Bytom Trough. Numerous foldings are a characteristic feature of this region. The inclination of the layers varies from 0 up to $70^{\circ}$. The coal deposit in this mine is intersected by many faults of different extents and throws. The two major faults in this region are the Grodziecki Fault and the Wojkowicko-Będziński Fault (Fig. 3). In the Grodziecki Fault the western side is thrown down, while in the Wojkowicko-Będziński Fault the SW side is thrown down. The throw values of the former fault vary from 170 to $250 \mathrm{~m}$, while in the case of the latter they are close to $170 \mathrm{~m}$. These faults divide the coal deposits into four tectonic blocks. In each of these blocks, the coal beds are located at different depths.

\section{MINING SETTINGS}

The Dabrowa Basin, as well as the Upper Silesian Coal Basin as a whole, is a paralic basin. Coal mining in this area began in the 18th century when the first mines were opened. The thickness of the coal beds in this area varies from several metres up to $24 \mathrm{~m}$ (Ciepiela, 2003). The coal beds are intersected by numerous faults with throws reaching over $300 \mathrm{~m}$. The average hade is $>0^{\circ}$, which makes the mining operations very difficult. Over the years, the extraction depth has significantly increased and nowadays it exceeds $500 \mathrm{~m}$. The most common exploitation system in all mines of the basin is the longwall system without backfilling. In some cases, when the mining conditions are difficult, the shortwall or other special systems are used

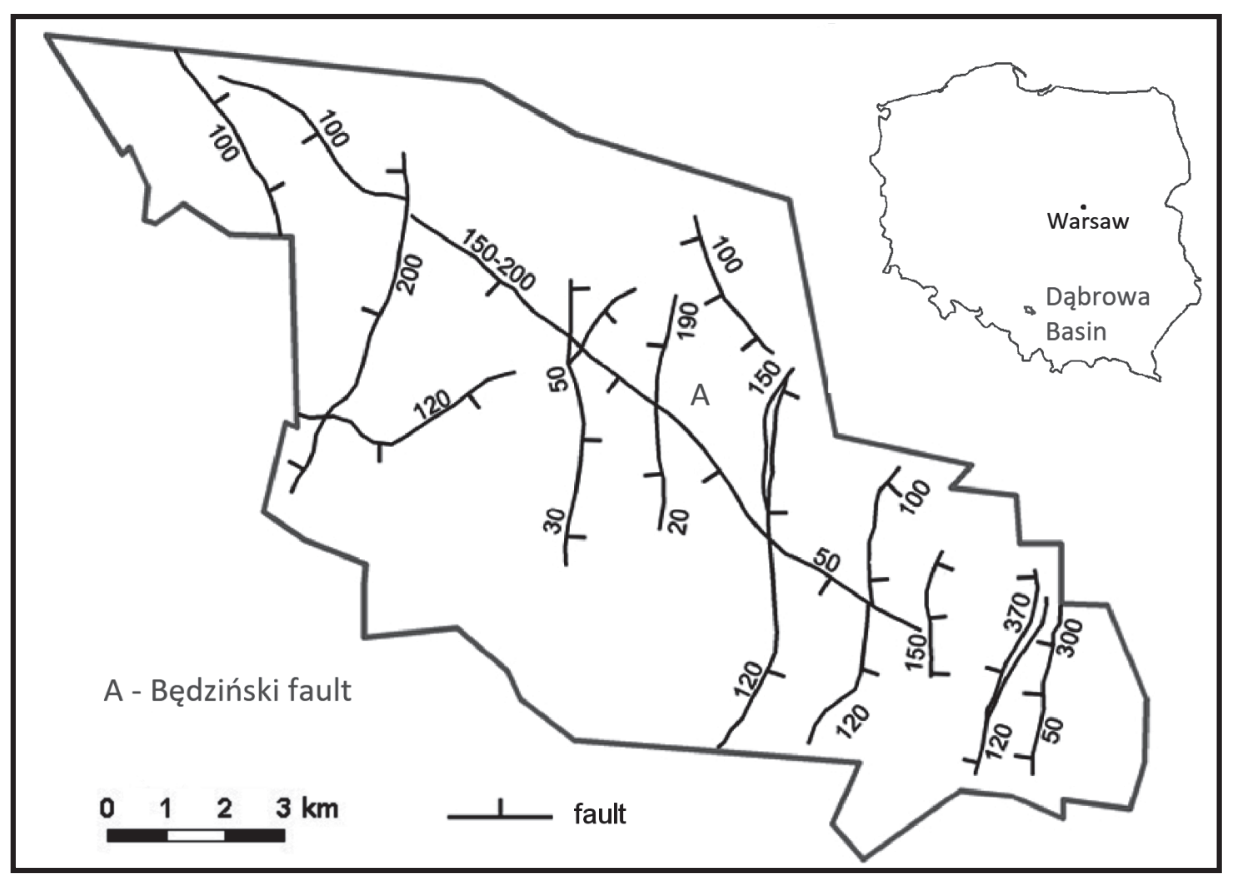

Fig. 1. The Dabrowa Basin region and the location of major faults 


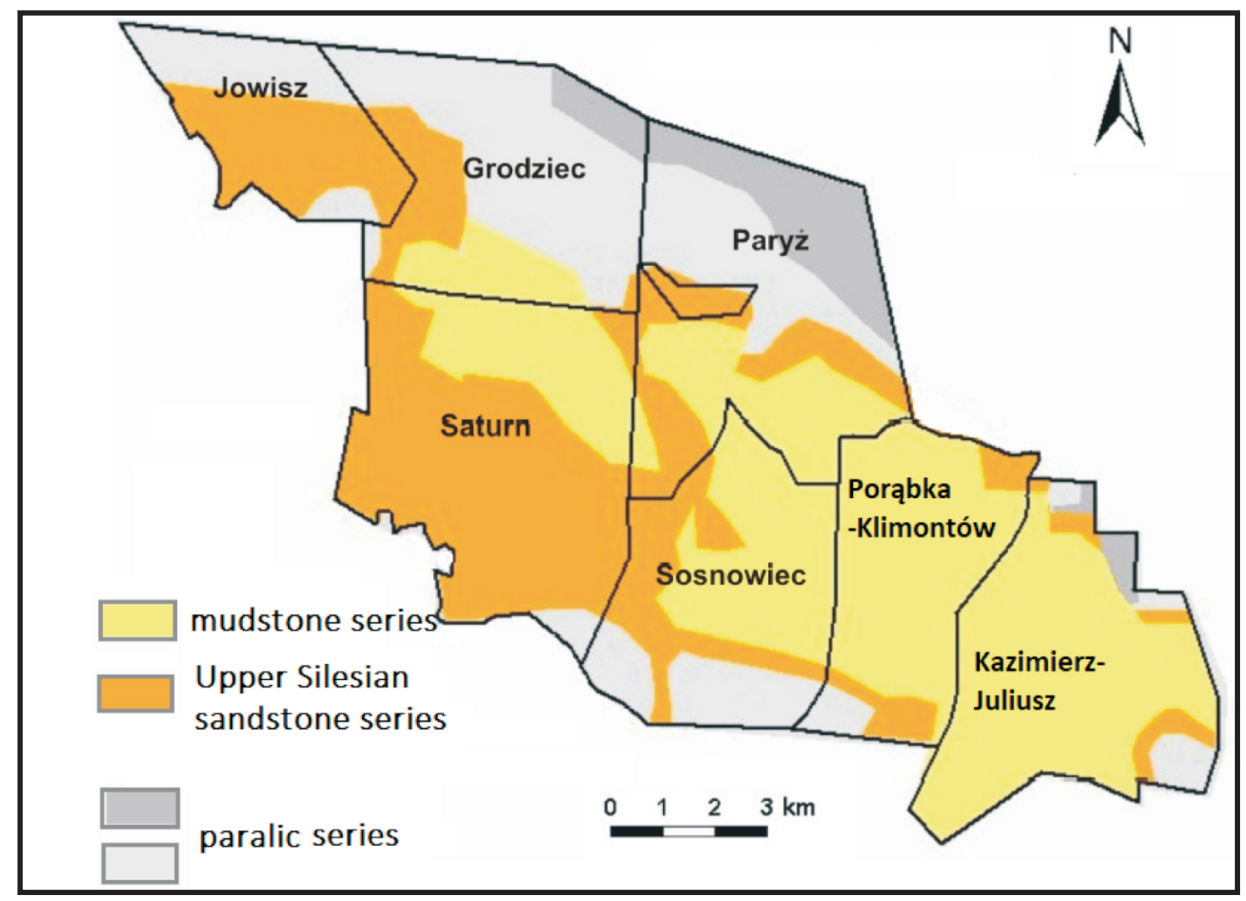

Fig. 2. The range of productive Carboniferous rocks in the analysed part of the Dabrowa Basin

(Ciepiela, 2003). Only a very small percentage of coal mines utilize a longwall system with backfilling. There are seven coal mines located in the Dabrowa Basin: "Kazimierz-Juliusz", "Porabka-Klimontów", "Sosnowiec", "Paryż", "Saturn", "Grodziec" and "Jowisz" (Fig. 4). Almost all of them were closed between 1995 and 2004. The only still active mine is the "Kazimierz-Juliusz".

The "Grodziec" coal mine is located in the northern part of the Dabrowa Basin. Its mining area is divided by faults into four tectonic blocks: A-D (Fig. 3). Coal extraction began in this mine in 1901. During the period covered by the present study (1992-2003), the exploitation was concentrated in the $\mathrm{SW}$ block (block $\mathrm{B}$ ). Coal was mined from a depth of $\sim 500$ m. In 1992, the annual output of the "Grodziec" coal mine was $\sim 627,300$ tonnes. During the study period, its annual output decreased to 449,740 tonnes (in the year 1998). The last tonne of coal was extracted in the mine in December 1998. The mine was closed as coal exploitation had become unprofitable due to very difficult geological conditions.

\section{ANALYSIS OF GROUND DEFORMATION IN THE DĄBROWA BASIN}

Different types (continuous and discontinuous) of ground deformation were observed within the area of the Dabrowa Basin. They differ in scale and intensity. The large-scale deformations are mainly continuous and with slower rate than the small-scale deformations that can be much faster and can create discontinuous dislocations. The ground deformations in the Dabrowa Basin are usually monitored using precise surface levelling. Geodetic measurements of deformations are routinely made in mining areas since they are mandatory under the Polish Geological and Mining Law. They are re- peated continuously at the same measurement point network during the entire exploitation period. Unfortunately, these regular measurements are very expensive, especially in the case of large-area monitoring.

Measurements of vertical ground displacements caused by mining activity in the USCB (including the Dabrowa Basin) were also made with classic satellite radar interferometry (DInSAR Differential Interferometry SAR), which made it possible to monitor the formation of subsidence troughs caused directly by coal mining. The DInSAR analysis performed in the USCB revealed the occurrence of subsidence in areas where coal ex-

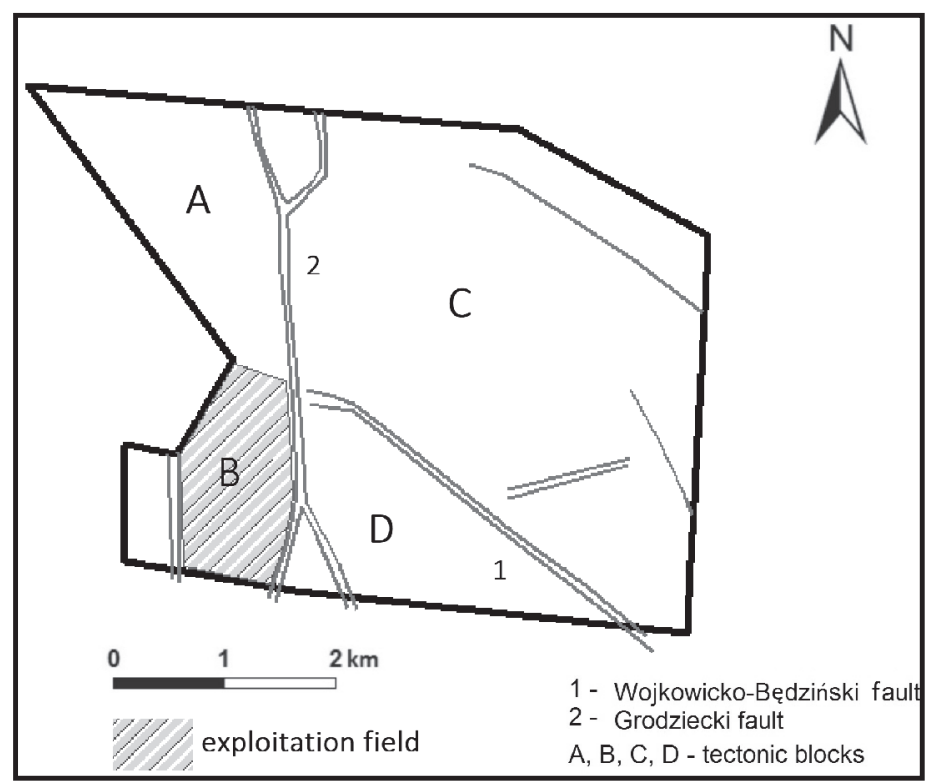

Fig. 3. Mining area of the "Grodziec" coal mine and the location of major faults and the exploitation field 


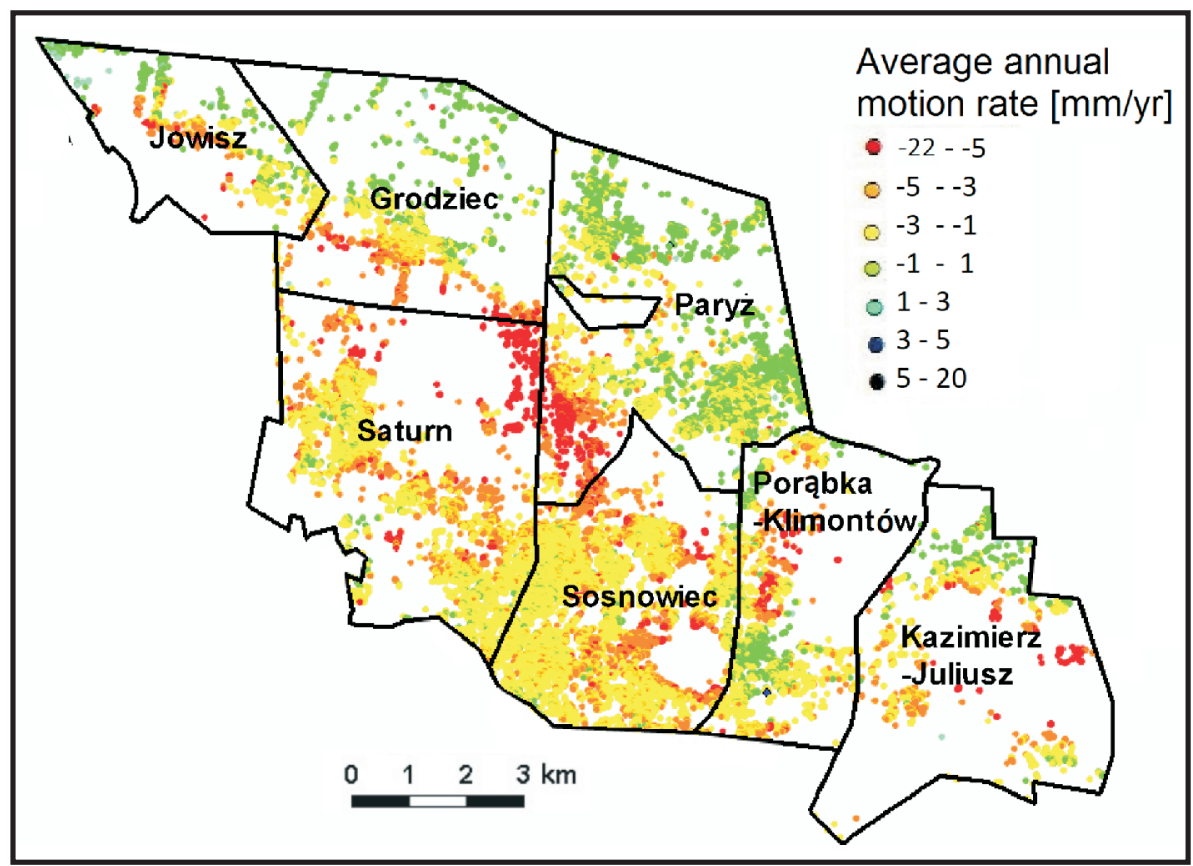

Fig. 4. The Dąbrowa Basin, and the location of PS points and boundaries of mining areas

ploitation had been conducted (Perski, 1999). The results are very useful for assessing the impact of mining activity on surface stability.

In addition to research aimed at monitoring deformation caused directly by coal exploitation, very slow, long-term vertical ground displacements were also measured in this area. The first study of such deformations was conducted in 1960 and based on levelling data obtained during the periods 1926-1937 and 1953-1955. The next analysis of Earth's crust movements in Poland was performed in 1977-1987. In this case, levelling data from 1947-1950 and 1974-1982 were used. In 2006, researchers determined the velocities of vertical ground displacements in Poland, again on the basis of levelling data (from the two levelling campaigns of 1974-1982 and 1997-2003) as well as on mareographic data (Kowalczyk, 2007). The straightforward conclusion from this analysis is that, among other things, the Dabrowa Basin area is subsiding. The measurements taken in this area revealed a subsidence rate equal to $-3.5 \mathrm{~mm} /$ year. It can be also observed that the subsidence rate in the Dabrowa Basin increases from NE to SW.

\section{DATA USED}

In the present study, in order to investigate the pattern of surface deformations in the Dabrowa Basin, the authors made use of PSInSAR data obtained within the framework of the GMES (Global Monitoring for Environmental and Security) project.

\section{PSInSAR TECHNIQUE}

The PSInSAR technique was developed at the end of the 20 th century. It involves using a large set of SAR images to de- tect small, long-term ground deformations (Ferretti et al., 2001). A review of PSI methods can be found in Crosetto et al. (2016).

The PSInSAR technique is widely applied in the Earth sciences. Examples include as follows: tectonic activity (Massironia et al., 2009; Antonielli et al., 2016), hydrogeological problems related to water extraction (Declercq et al., 2005; DePrekel et al., 2018), volcanic eruptions (Ferretti et al., 2008), seismicity pattern analysis (Lagios et al., 2012), measurements of displacements caused by earthquakes (Ishitsuka et al., 2015), and mining-induced ground deformation monitoring (Huang et al., 2019).

\section{PSInSAR DATA FOR THE DAZBROWA BASIN AND "GRODZIEC" COAL MINE}

The PSInSAR data used in this study were computed on the basis of 79 selected SAR images gathered by ERS-1, ERS-2 and ENVISAT satellites between 1992 and 2003. Most of the images were collected with a 35-day temporal baseline. However, the analysed dataset also features several temporal baselines longer than 35 days (mainly 70 days) and 8 temporal baselines equal to 1 day. The radar image processing was performed entirely by the Milan-based Italian company TRE (Tele-Rilevamento Europa) and supplied to the authors within the framework of the GMES programme. SAR data processing helped identify 24723 PS points in the Dabrowa Basin (Fig. 4 ). The average deformation velocity (in $\mathrm{mm} /$ year) and coherency were determined for each PS point. In addition, the relative deformations between each satellite image and the reference image (acquired at 13.08.1997) were assessed for 6105 PS points.

The PS points are unevenly distributed in the Dabrowa Ba$\sin$. There are hardly any PS points in some parts of the studied region (outside urban areas) while in other parts (in the main cit- 


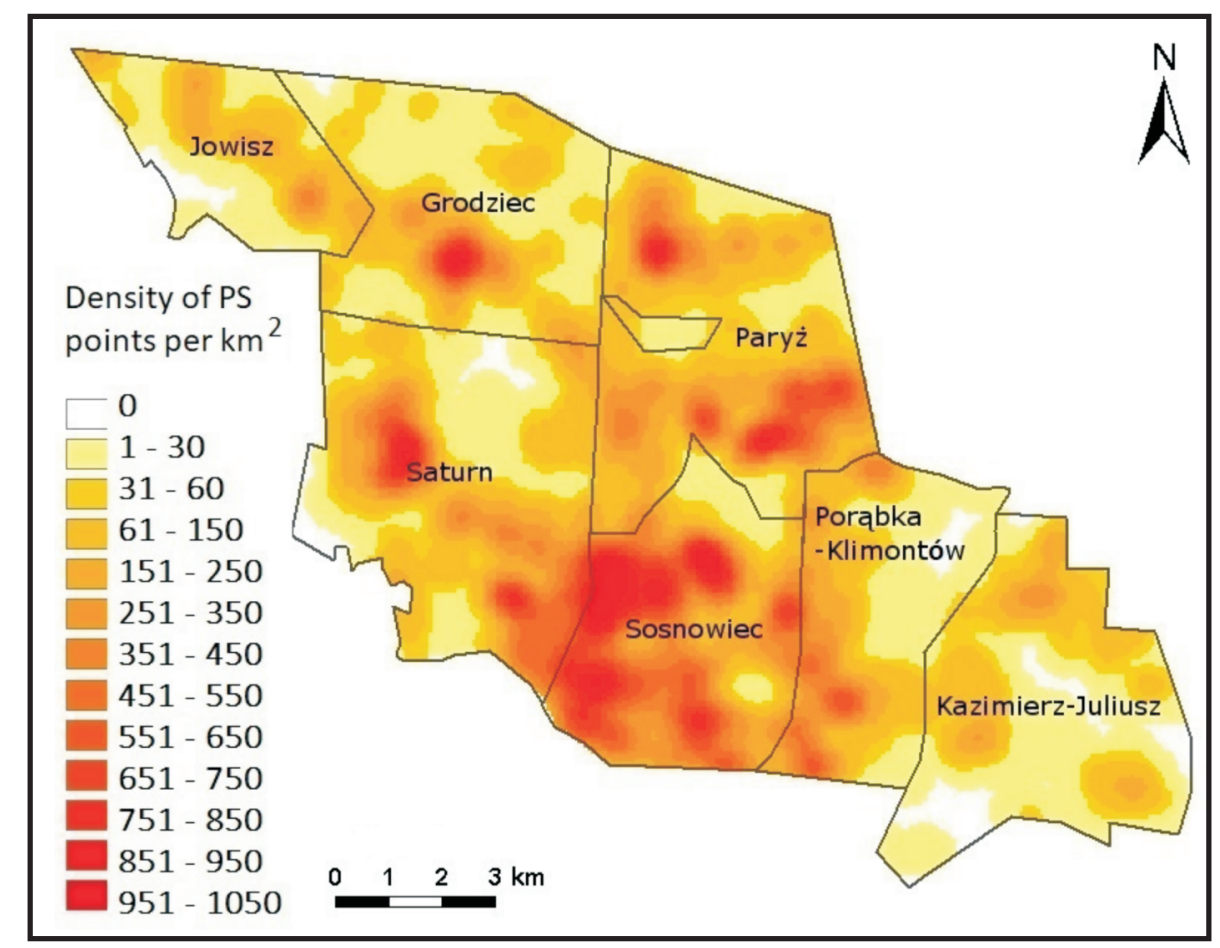

Fig. 5. The density of PS points in the Dąbrowa Basin

ies) their density exceeds 1000 PS points per $\mathrm{km}^{2}$ (Fig. 5). The PS point density is very low in forests and agricultural areas $\left(<100\right.$ PS points per $\left.\mathrm{km}^{2}\right)$, as well as in areas where subsidence rate is too high to be detected by means of the PSInSAR method and C-band SAR images.

A more detailed analysis was performed for the "Grodziec" coal mine in the town of Bedzin. Its mining area contains 1846 PS points (Fig. 6). Five hundred and thirty-six PS points from this set provide a detailed history of deformations in a 35-day time period. The distribution of PS points in this mining area is uneven. The built-up areas are located mainly in the central part of the mining area and this is the region where most of the PS points were identified. In some parts, where the levelling survey revealed intensive subsidence, only a small number of PS points are observed. The reasons are poor coherence $(<0.3)$, the processing method used, and a radar wavelength which was too short to evaluate unambiguously the reflector shift between two time-adjacent radar images.

\section{PSInSAR DATA ANALYSIS}

Previous studies revealed a significant correlation between small, long-term ground deformation and the location of the main tectonic units in the Upper Silesian Coal Basin (Graniczny et al., 2008; Leśniak and Porzycka, 2009b). The authors of the study performed spatial and temporal analyses based on PSInSAR in the Dabrowa Basin. The purpose of these analyses was to study additional correlations, namely the interconnection between ground deformation values and mining activity.

\section{SPATIAL ANALYSIS OF PSInSAR DATA}

The aim of the first stage of PSInSAR data spatial analysis was to identify a regional trend. This trend was studied for different directions. In Figure 7, the ground deformation velocities measured for the PS points were projected onto perpendicular NW-SE and SW-NE planes. Best-fit polynomial models were drawn up for both directions. The trend was only identified for a SW-NE direction that is perpendicular to the line of the Będziński Fault. In the case of the SW-NE direction, the deformation values are increasingly negative. The biggest change in deformation velocities occurs near the line of the Będziński Fault.

The shape of the SW-NE trend shown in Figure 7 suggests the use of second-order polynomial for regional trend approximation. To model the trend and create a smooth surface, the authors applied the local polynomial interpolation method.

The results show (Fig. 8) that the Będziński Fault divides the studied region into two parts with different deformation velocities. In the case of the downthrown block, subsidence was the predominant feature, most intense in the central part (near the fault line) and in the eastern part (in the mining area of the "Kazimierz-Juliusz" coal mine) of the region. In the upthrown block of the Będziński Fault, deformation rates decrease to $0 \mathrm{~mm} /$ year in a NE direction. The mean value of ground deformation velocities in the downthrown block of the fault is equal to $-2.7 \mathrm{~mm} / \mathrm{yr}$, and for the upthrown block it is $-0.7 \mathrm{~mm} / \mathrm{yr}$. These results confirm previous studies, which showed that the deformation values are strongly associated with the location of tectonic units in the Dąbrowa Basin (Graniczny et al., 2008). 


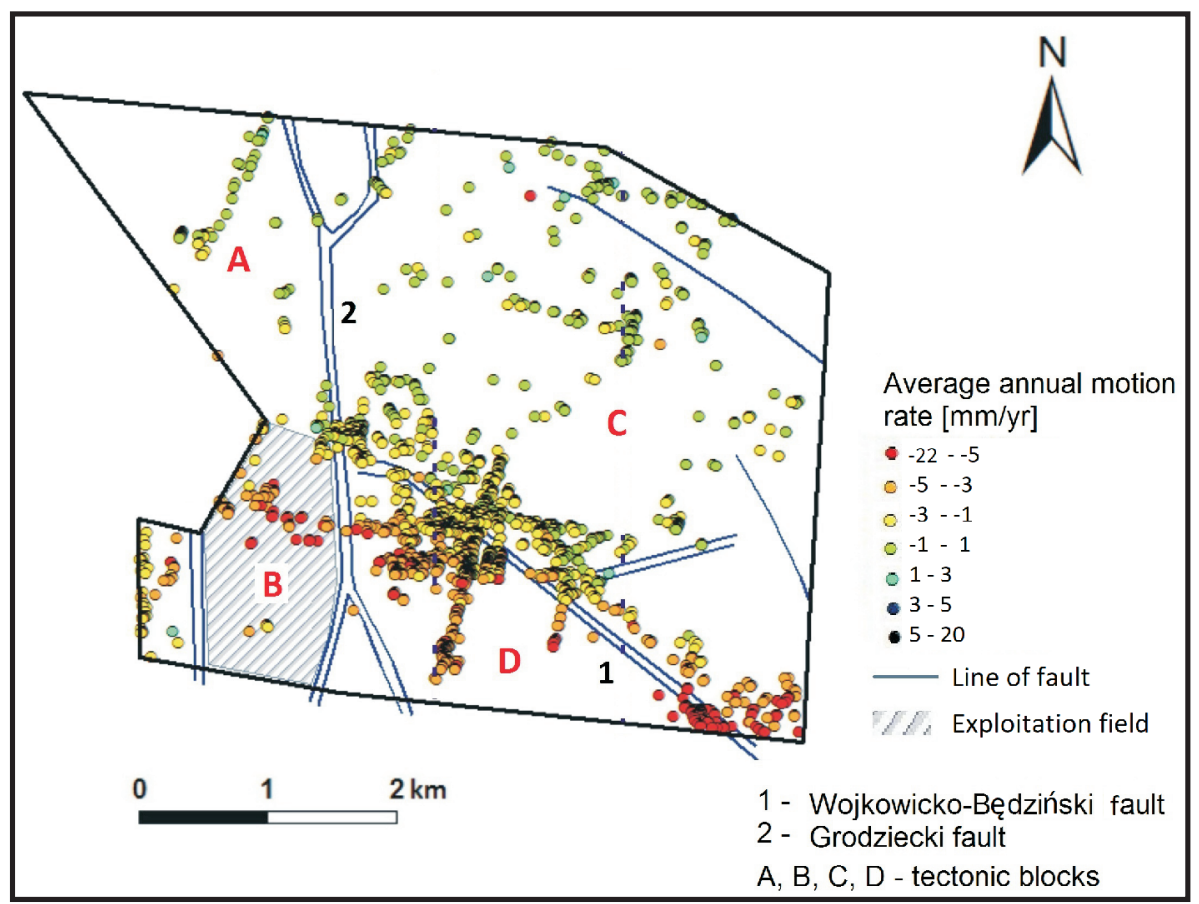

Fig. 6. Mining area of the "Grodziec" coal mine, featuring PSInSAR data

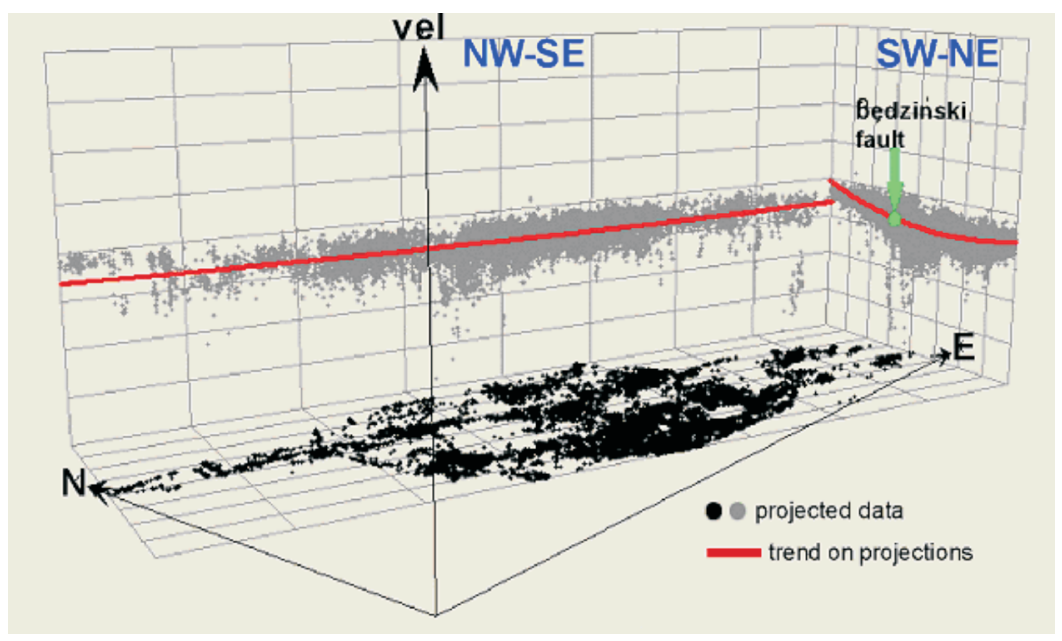

Fig. 7. Trend analysis in directions parallel and perpendicular to the line of the Będziński Fault

Besides the existence of a regional trend, local factors may affect surface stability. To analyse short-range variations in ground deformation velocities, the detected trend was removed from the PSInSAR data and the obtained residuals were further analysed.

The spatial autocorrelation and directional variation of residual ground deformation velocities were studied using geostatistical methods. These methods can be used to analyse data that are spatially and/or temporally correlated (Weckernagel, 1995). First, to study anisotropy, the authors calculated the directional semivariograms. A semivariogram plots the semivariance between data points as a function of distance. The values of these semivariograms were estimated by Equation 1:

$$
\gamma(\vec{h})=\frac{1}{2 N_{\vec{h}}} \sum_{i=1}^{N_{\hat{h}}}\left[z\left(s_{i}\right)-z\left(s_{i}+\vec{h}\right)\right]^{2}
$$

where: $N_{\vec{h}}$ is a number of pairs of point $z\left(s_{i}\right), z\left(s_{i}+\vec{h}\right)$ linked by vector $\vec{h}$. In the present study, directional semivariograms were calculated for the following azimuths: $0^{\circ}, 30^{\circ}, 60^{\circ}, 90^{\circ}, 120^{\circ}$ and $150^{\circ}$ (Fig. 9).

The analysis revealed the occurrence of geometrical anisotropy. The range of autocorrelation in an approximately NE direction (azimuth $60^{\circ}$ ) is clearly greater than the range in an approximately SE direction (azimuth $150^{\circ}$ ). The empirical semivariograms were fitted by spherical models (Fig. 9). The theo- 


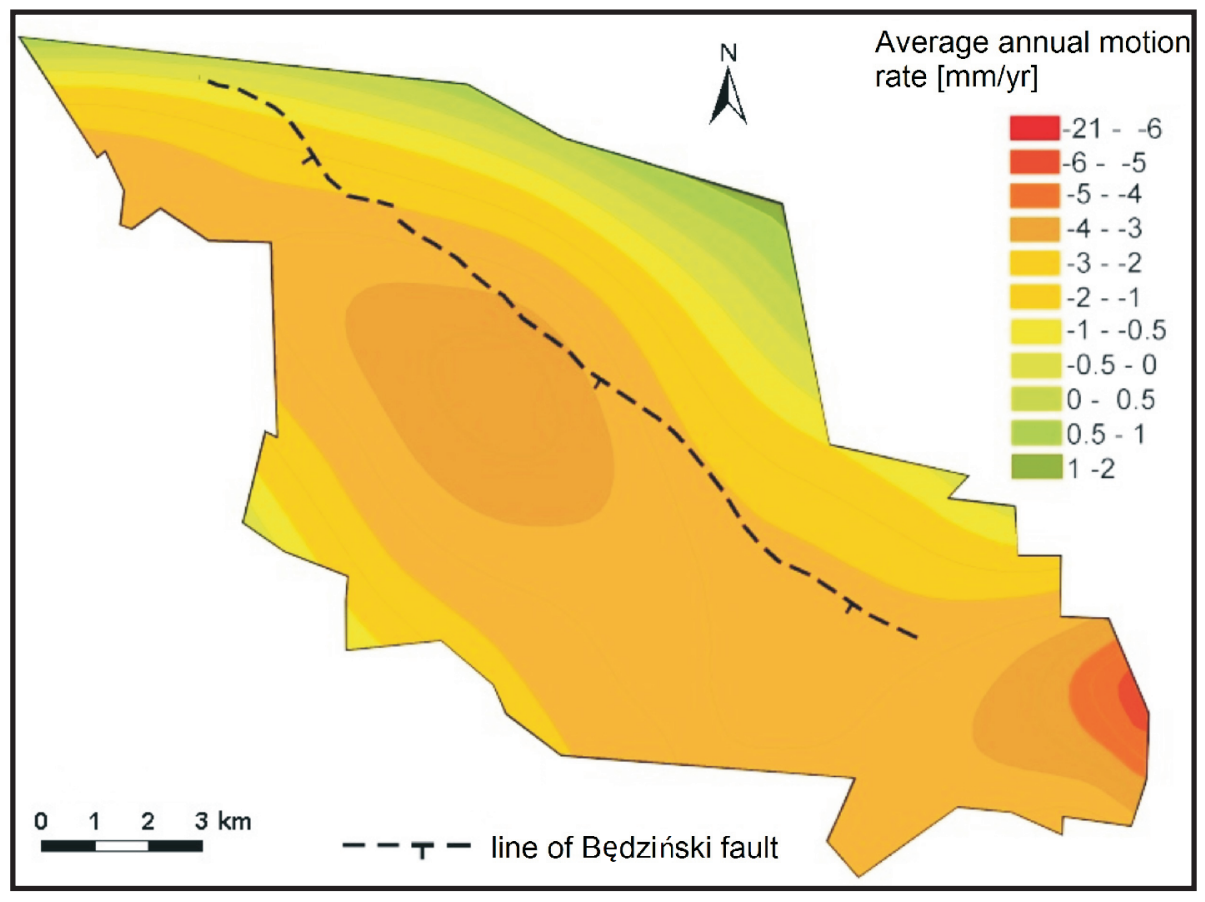

Fig. 8. Results of local polynomial interpolation of annual deformation velocities

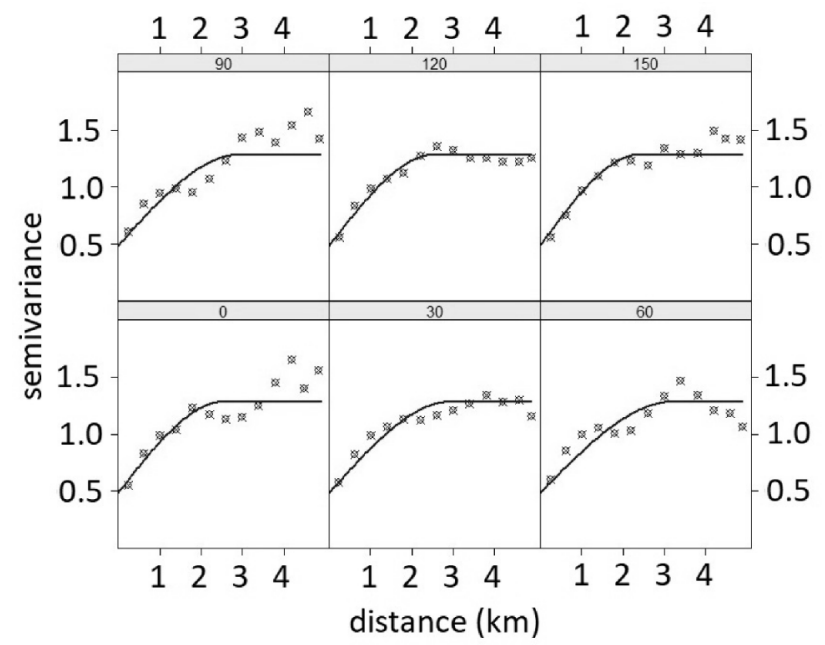

Fig. 9. Empirical directional semivariograms with fitted theoretical models

retical model obtained for an azimuth equal to $60^{\circ}$ takes the form presented in Equation 2.

$$
\gamma=\left\{\frac{\left\{0.8\left[1.5\left(\frac{\mathrm{h}}{3.21}\right)-0.5\left(\frac{h}{3.21}\right)^{3}\right]+0.48, \text { if } h \leq 3.21\right\}}{1.28, \text { if } h>3.21}\right\}
$$

The range of autocorrelation for this azimuth is equal to $3.21 \mathrm{~km}$. The anisotropy ratio is equal to 1.33 , which means that the range of autocorrelation for azimuth $60^{\circ}$ is 1.33 times greater than the range for azimuth $150^{\circ}$. The detected geometrical anisotropy was incorporated into subsequent procedures.
To interpolate the ground deformation velocities at unmeasured points, the ordinary kriging technique was used for residual data. This method results in predictions in the form shown in Equation 3:

$$
z_{o k}=\sum_{i=1}^{n} w_{i}\left(s_{0}\right) z\left(s_{i}\right)
$$

where: $w_{i}$ are the kriging weights, and $z\left(s_{i}\right)$ is the value of the parameter measured at location $s_{i}$.

The kriging weights are determined on the basis of information on the spatial autocorrelation between the data quantified and described by semivariograms. The kriging results are presented in Figure 10. Within the studied region of the Dąbrowa Basin there are clearly several areas with high subsidence values that were not revealed on the map obtained using the local polynomial interpolation method. Most of these areas are located in the downthrown block of the Będziński Fault in the mining areas of the "Kazimierz-Juliusz", "Porąbka-Klimontów", "Saturn" and "Jowisz" coal mines.

In addition to the kriging results, a prediction variance map was also calculated (Fig. 11). This makes it possible to asses errors in the interpolation procedure. The prediction variance values were calculated using Equation 4.

$$
\sigma_{\text {ок }}=C-\sum w_{i}\left(s_{0}\right) C\left(s_{0}, s_{i}\right)+\varphi
$$

where: $C\left(s_{0}, s_{i}\right)$ is a covariance between the interpolated point and data point, $C$ is a sill (horizontal asymptote) of semivariogram, and $\varphi$ is called a Lagrange multiplier.

The highest kriging errors occur within the mining areas of the "Jowisz" and "Kazimierz-Juliusz" coal mines. 


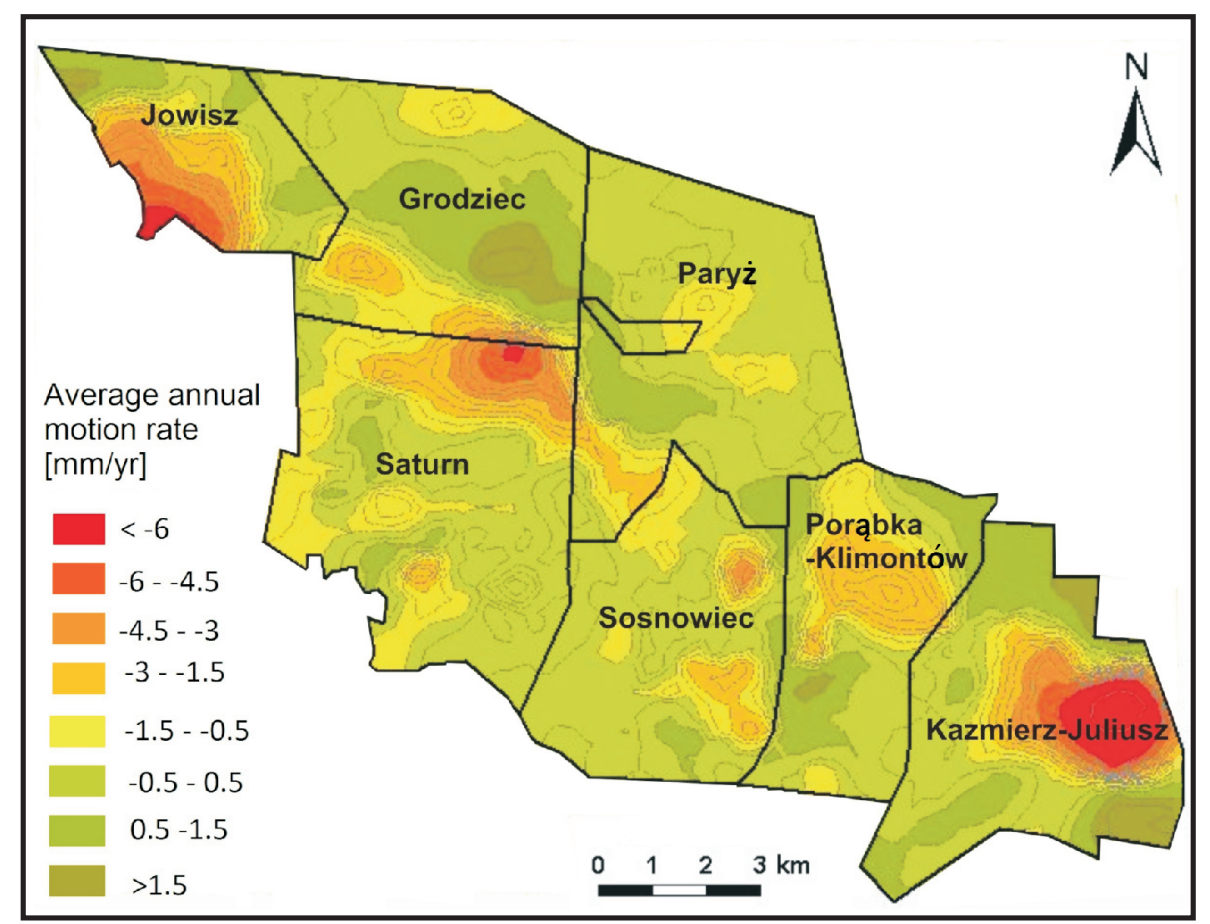

Fig. 10. Map of kriging results

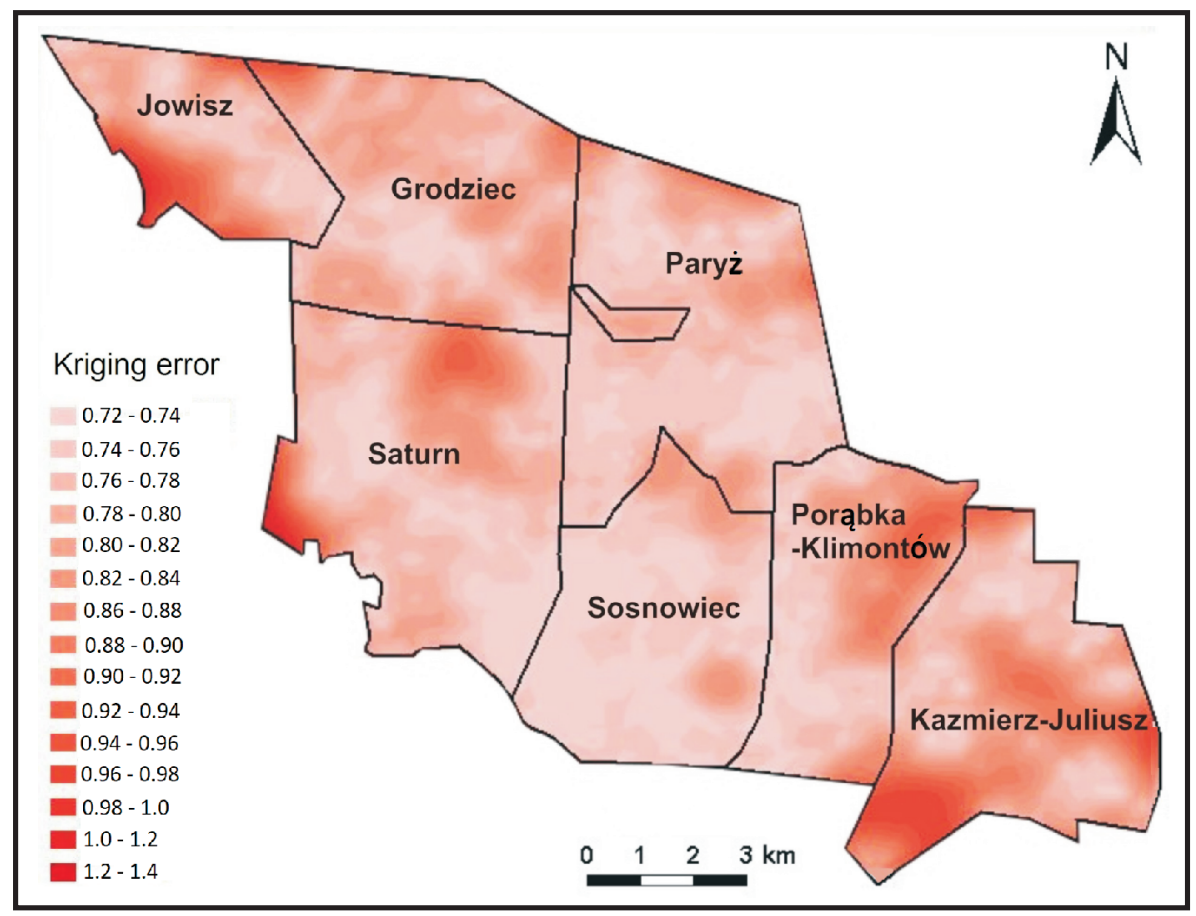

Fig. 11. Map of kriging error

The results may indicate that the identified regional trend may be the result of neotectonic movements and any short-range variation may be caused by more temporal features such as coal exploitation. To verify this hypothesis the authors performed a temporal analysis of the PSInSAR data.

\section{TEMPORAL ANALYSIS OF PSInSAR DATA}

The ground deformation values obtained by means of the PSInSAR technique depend on many local factors that affect 
particular stable radar targets. In many cases, deformation values approximated for a PS point on the basis of a linear model (as is done in the standard PSInSAR algorithm) result in the loss of important information (Gehlot et al., 2005). Such a situation may lead to erroneous interpretations of deformation measurements. On the other hand, over-interpretation may amplify the irrelevant factors.

In the present article, the authors performed a temporal analysis of the PSInSAR data. The aim of this part of the study was to examine trend changes in ground deformation values for each PS point. In order to perform this task a special algorithm was developed. The algorithm was proposed by Porzycka and Leśniak (2010). The algorithm makes it possible to approximate the ground deformation values for each PS point using two lines.

The algorithm was designed to ensure fast and precise analysis of large PSInSAR datasets. All its parts were performed using the $R$ statistical computing environment. The $R$ is based on S language (Rizzo, 2007).

In the first step of the algorithm, all 79 deformation values measured between the years 1992 and 2003 were approximated for each PS point using two lines. The first of these lines was matched to the first $n$ measurements, while the second was matched to the other (79-n) measurements. For each stable radar, target value $n$ varies between 15 and 63, so the approximation is performed for a minimum of 15 values. Such a solution allows any trend change to be detected within a narrower time period between X.1993 (the 15th measurement) and IV.2000 (the 63rd measurement).

In the next step of the algorithm, the authors tested if the fitted models satisfy the assumptions of linear regression. The normality distribution of residuals was determined for each model, using the Shapiro-Wilk test (Sen et al., 1990). In a correctly estimated model, the residuals are normally distributed. The constancy of residuals was assessed for each model using the Breusch-Pagan test. The variable variance of residuals may indicate that the used model is unreliable because the residuals are not random. In the next step, the algorithm assesses the presence of any autocorrelation between the residuals. To perform this task the Durbin-Watson test (Sen et al., 1990) was used. The presence of autocorrelation may indicate the existence of a factor which was not included in the model. As a result of this part of the study, only pairs of lines meeting three conditions (the residuals are normally distributed, have constant variance, and zero correlation) were chosen for each PS point. The PS points that could not be approximated using two lines were not taken into consideration later in the study.

In the third part of the algorithm, the best fitted pair of lines was chosen for each PS point. In order to do this the determination coefficient $R^{2}$ and the regression standard error RSE were calculated for each estimated model.

In the final part of the algorithm, the differences in the slopes of fitted models were determined for each PS point. If the difference was $>20^{\circ}$, the PS point together with the date and category of trend change were recorded. In the present study, the trend changes were divided into four categories:

category I - increase in subsidence velocity,

category II - decrease in subsidence velocity,

category III - increase in ground lifting velocity,

category IV - decrease in ground lifting velocity.

The proposed temporal analysis was performed at 6105 PS points. Trend changes were identified in 2520 of them. The results of the analysis are shown in Table 1. More detailed insights into the results can be found in Porzycka et al. (2010).

Temporal analysis of PSInSAR data revealed that trend changes occurred in $41 \%$ of all the stable radar targets included
Table 1

\section{Results of temporal analysis of PSInSAR data} for the Dabrowa Basin

\begin{tabular}{|l|c|}
\hline Time period/category & Number of PS points \\
\hline X.93-XI.94 & 544 \\
\hline XI.94-XII.95 & 431 \\
\hline XII.95-I.97 & 160 \\
\hline I.97-II.98 & 102 \\
\hline II.98-III.99 & 155 \\
\hline III.99-IV.2000 & 1128 \\
\hline Total & 2520 \\
\hline
\end{tabular}

in the analysis. The table shows that the number of PS points for which trend changes were detected varies in time. Most changes occurred between X.1993 and XII.1995 (almost 38\% of all changes) and between III.1999 and IV.2000 (45\% of all changes). As can be read in Porzycka et al. (2010) an increase in subsidence velocity is a typical feature of the first of these time periods (category I), while a decrease in subsidence velocity was the most common trend change (category II) in the second period. Such a situation may indicate that some factors affecting ground deformation values occurred during these time intervals.

The results of PSInSAR data temporal analysis were analysed separately for the mining area of the "Grodziec" coal mine. In this region, 536 stable radar targets were identified. The results of the analysis are presented in Table 2. More detailed insights into these results can be found in Porzycka et al. (2010).

Table 2

Results of temporal analysis of PSInSAR data for the "Grodziec" coal mine

\begin{tabular}{|l|c|}
\hline Time period/category & Number of PS points \\
\hline X.93-XI.94 & 31 \\
\hline XI.94-XII.95 & 32 \\
\hline XII.95-I.97 & 10 \\
\hline I.97-II.98 & 16 \\
\hline II.98-III.99 & 16 \\
\hline III.99-IV.2000 & 138 \\
\hline Total & 243 \\
\hline
\end{tabular}

The table shows that trend changes occurred in nearly $46 \%$ of all the PS points from the "Grodziec" mining area. Most of these changes (56.8\%) occurred between III.1999 and IV.2000. As was revealed in Porzycka et al. (2010) these are category II changes involving a decrease in subsidence velocity. Twentysix percent of trend changes occurred within the first 26 months of the analysed time interval. These are mostly category I changes (increase in subsidence velocity).

The aim of the next stage in the present study was to analyse the spatial distribution of PS points for which trend changes were detected in successive time intervals. To perform this task, maps of relative density of PS points were prepared for the time periods in which most trend changes were detected. The relative density of values of PS points was determined using a two-dimensional kernel density estimator (KDE).

Kernel estimation is a nonparametric method. It makes it possible to estimate the density function values of a random 
variable based on a finite number of data points (Walter and Gotway, 2004). The estimator of two-dimensional density function at point $s=\left(u_{0}, v_{0}\right)$ takes the form presented in Equation 5 (Walter and Gotway, 2004)

$$
\tilde{f}\left(u_{0}, v_{0}\right)=\frac{1}{N b_{u} b_{v}} \sum\left\{K\left(\frac{u_{0}-u_{i}}{b_{u}}\right) K\left(\frac{v_{0}-v_{i}}{b_{v}}\right)\right\}
$$

where: $K$ is a kernel function, and $b_{u}$ and $b_{v}$ are estimation bandwidths for variables $u$ and $v$. In the present study, a Gaussian function [Equation 6] was used as a kernel function.

$$
K\left(\frac{u-u_{i}}{b}\right)=\frac{1}{\sqrt{2 \pi b}} \exp /\left[-\frac{1}{2}\left(\frac{u-u_{i}}{b}\right)^{2}\right]
$$

The smoothing of the surface thus obtained depends on the estimation bandwidths. In this work, values $b_{u}$ and $b_{v}$ were calculated using the formula proposed by Silverman (Equation 7; Silverman, 1986).

$$
b=0.9 \min \left(s, \frac{I Q R}{1.34}\right) N^{\frac{1}{5}}
$$

In the present study, the maps showing the relative density of PS points with trend changes were only prepared for two time periods in which the most of the changes were revealed. Firstly, the authors prepared the maps showing the relative density of PS points, for which trend changes occurred between X.1993 and XI.1994 (Figs. 12 and 13). These maps were prepared separately for trend changes falling within category I and those from category II. It ought to be mentioned that during this period of time all seven coal mines were in operation. Analysis of the maps revealed that during this period, category I trend changes were typical. Their high-density values are typical throughout al- most the entire study area, especially in the case of the downthrown block of the Będziński Fault. Category II trend changes were only detected in some areas in the upthrown block of the Będziński Fault.

In the second step, the authors prepared relative density maps of PS points for which trend changes occurred between III.1999 and IV.2000 (Figs. 14 and 15). The highest number of trend changes were detected during this time period. Most of them $(\sim 75 \%)$ indicate a decrease in subsidence velocity. It should be pointed out that only three coal mines were in operation during this time: "Kazimierz-Juliusz", "Jowisz" and "Porabka-Klimontów". In December 1999, the "PorabkaKlimontów" coal mine finished exploitation activity. The relative density of PS points with category II trend changes is high throughout almost the entire study region. The highest values were recorded within the mining area of the "Sosnowiec" coal mine. The relative density of PS points with category I trend changes was high in the mining area of the "Jowisz" coal mine. In this coal mine, exploitation activity continued until the end of IV.2000.

A separate analysis of relative density of PS points with trend changes was performed for the mining area of the "Grodziec" coal mine. Figures 16 and 17 present relative density maps of PS points for which trend changes occurred between X.1993 and XII.1995. These maps were prepared separately for category I and category II changes. They show that during the analysed time period, an increase in subsidence velocity was typical in areas near the exploitation field. On the other hand, category II trend changes are characteristic of the north part of the mining area.

Maps showing the relative density of PS points with trend changes in the "Grodziec" coal mine were also prepared for the time period between III.1999 and IV.2000 (Figs. 18 and 19). These indicate that during this time period, category II trend changes predominate throughout almost the whole mining area. A decrease in subsidence velocity is especially evident in

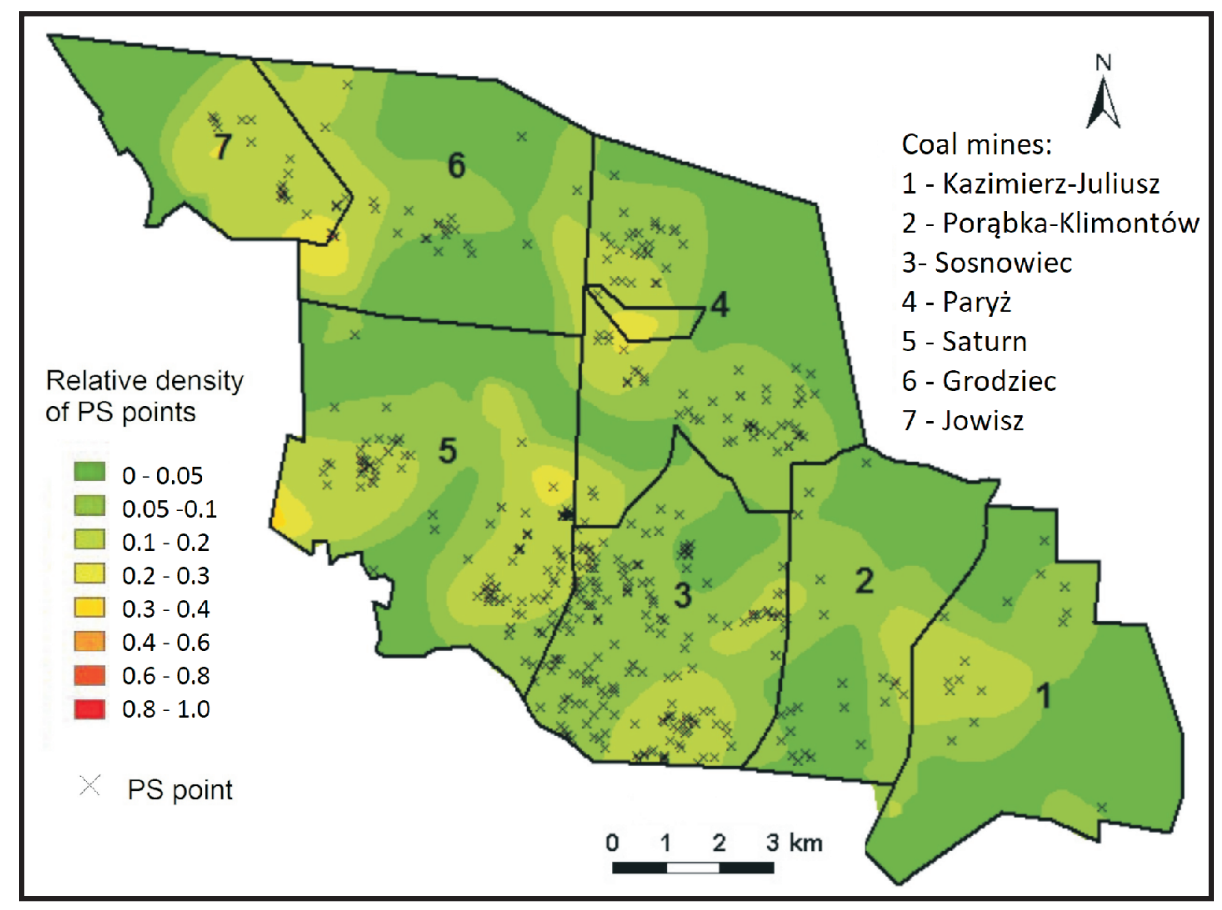

Fig. 12. The relative density of PS points for which trend changes occurred between X.1993 and XI.1994 (category I) 


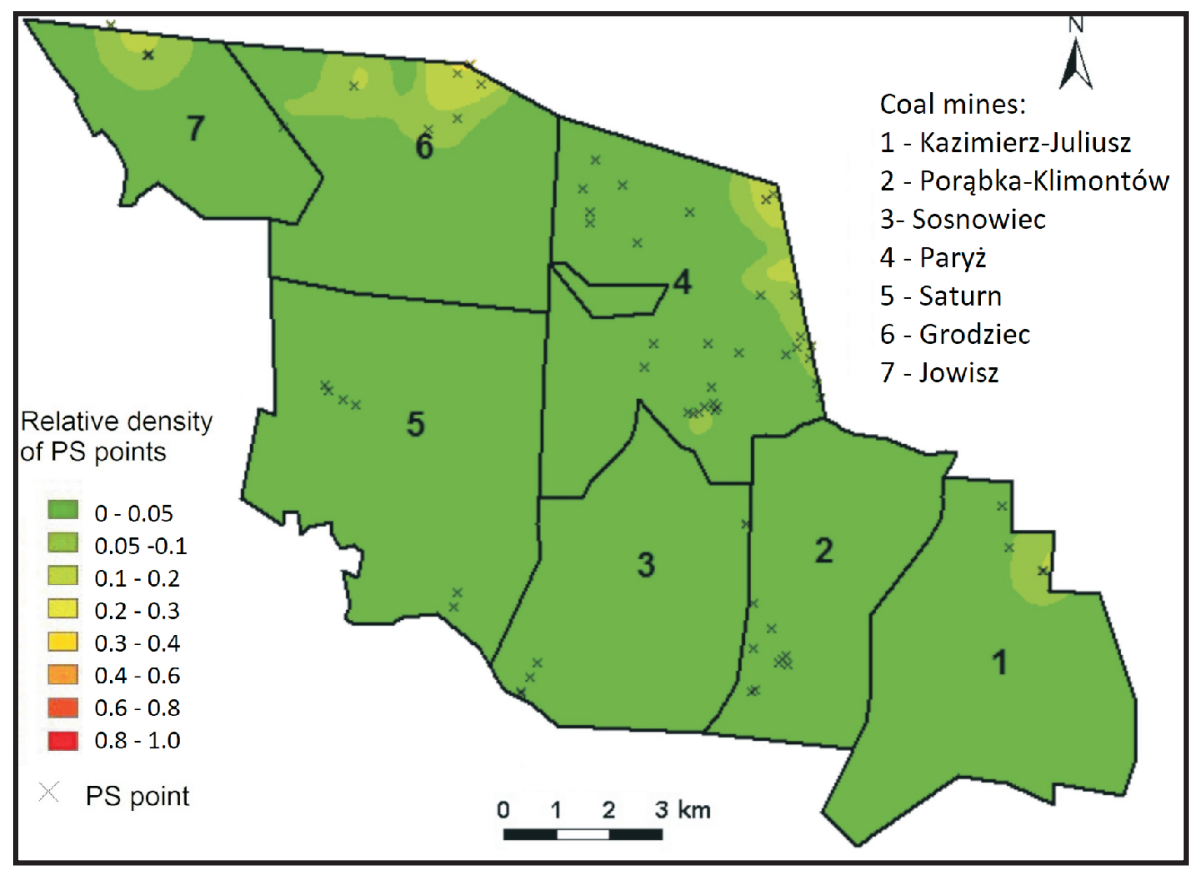

Fig. 13. The relative density of PS points for which trend changes occurred between X.1993 and XI.1994 (category II)

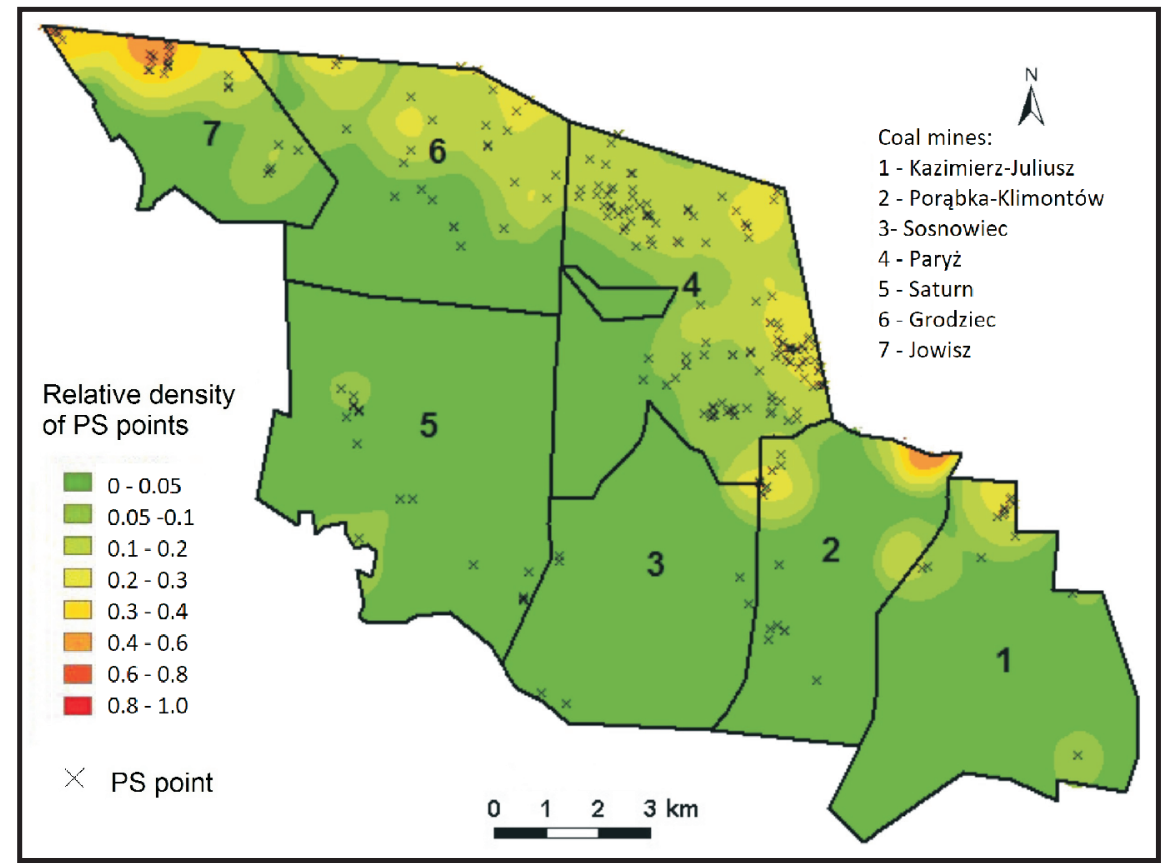

Fig. 14. The relative density of PS points for which trend changes occurred between III.1999 and IV.2000 (category I) 


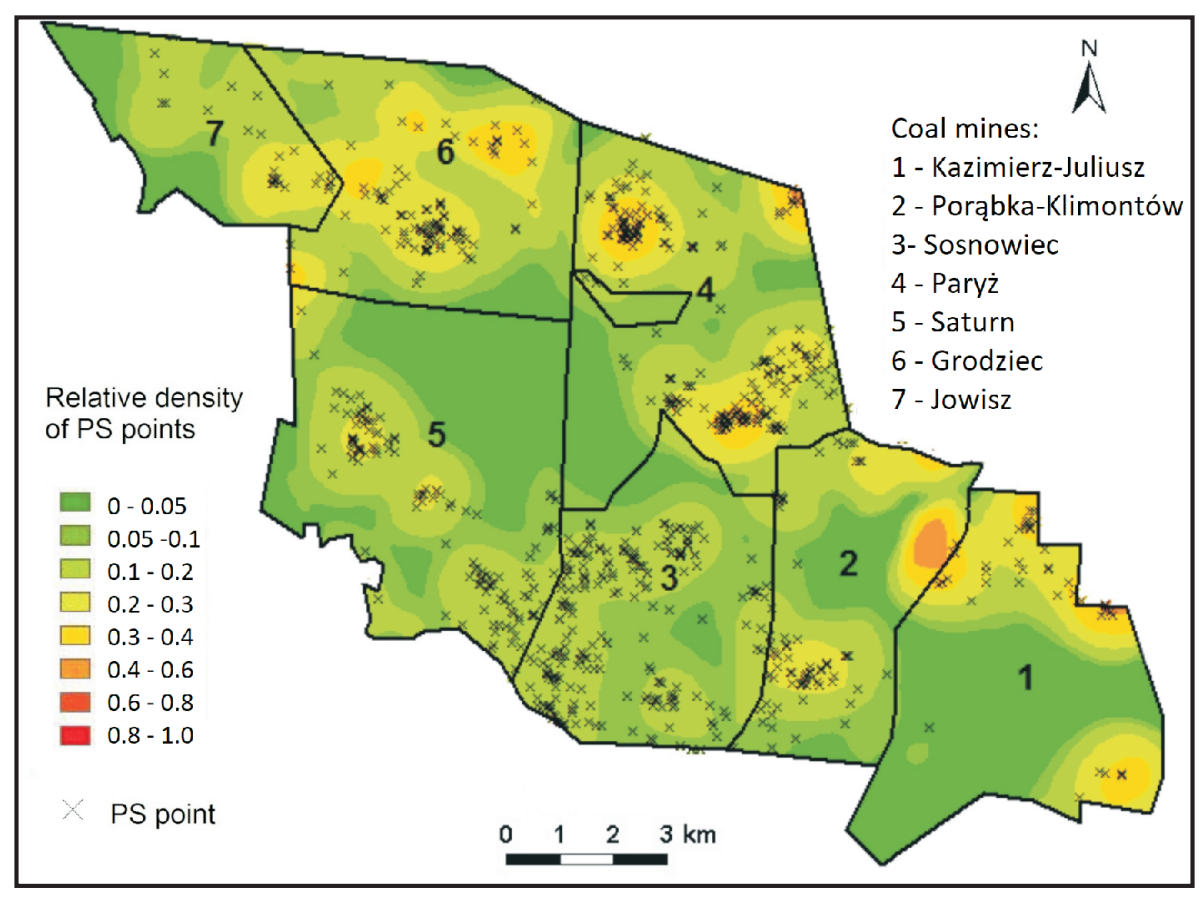

Fig. 15. The relative density of PS points for which trend changes occurred between III.1999 and IV.2000 (category II)

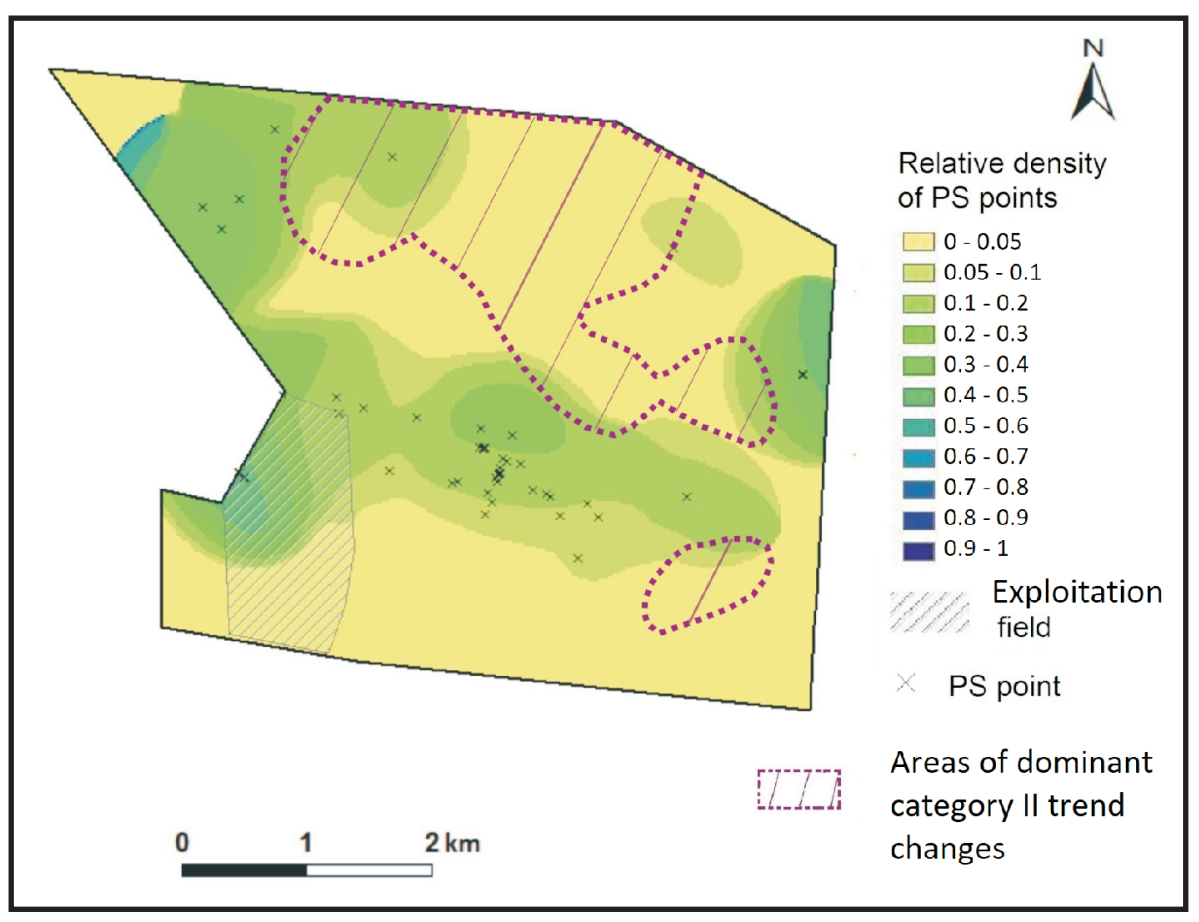

Fig. 16. The relative density of PS points for which trend changes occurred between X.1993 and XII.1995 (category I) 


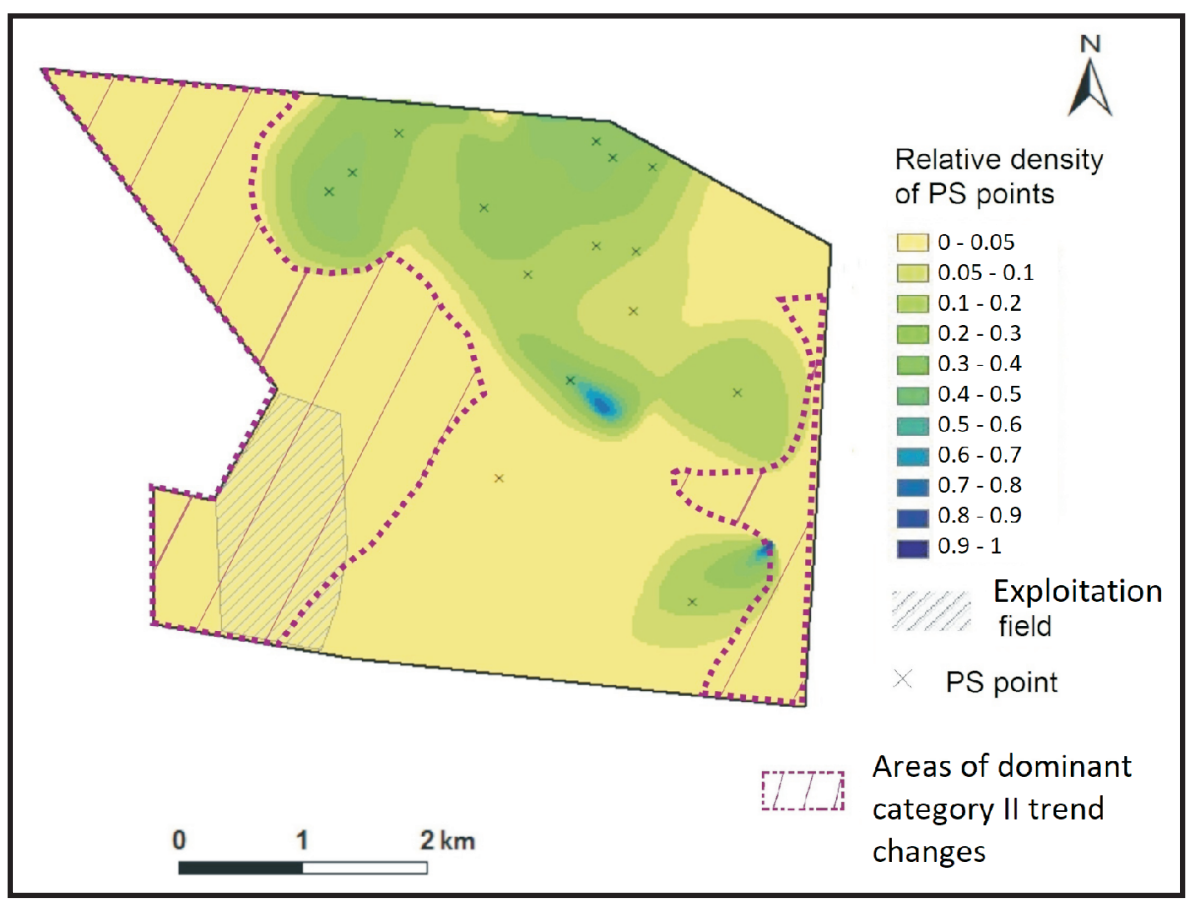

Fig. 17. The relative density of PS points for which trend changes occurred between X.1993 and XII.1995 (category II)

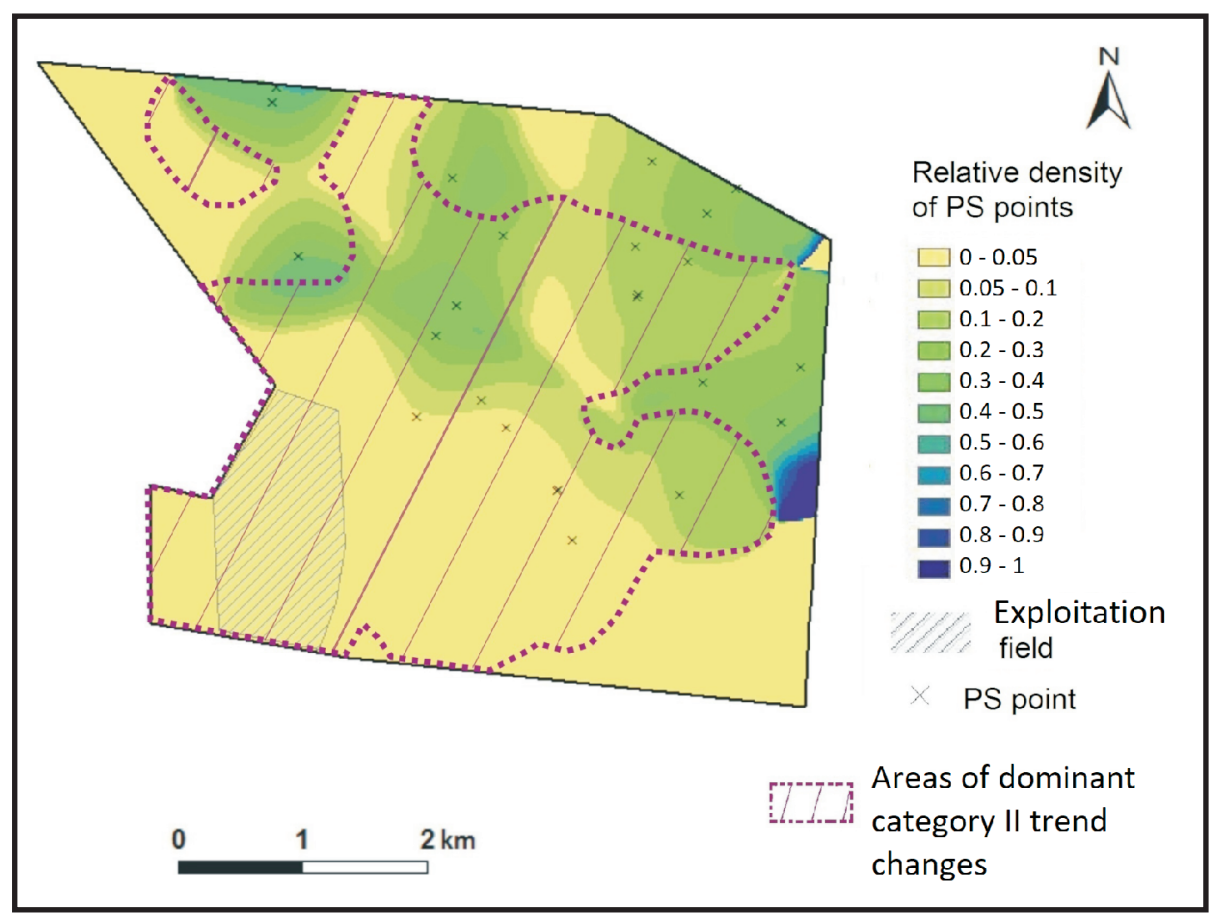

Fig. 18. The relative density of PS points for which trend changes occurred between III.1999 and IV.2000 (category I) 


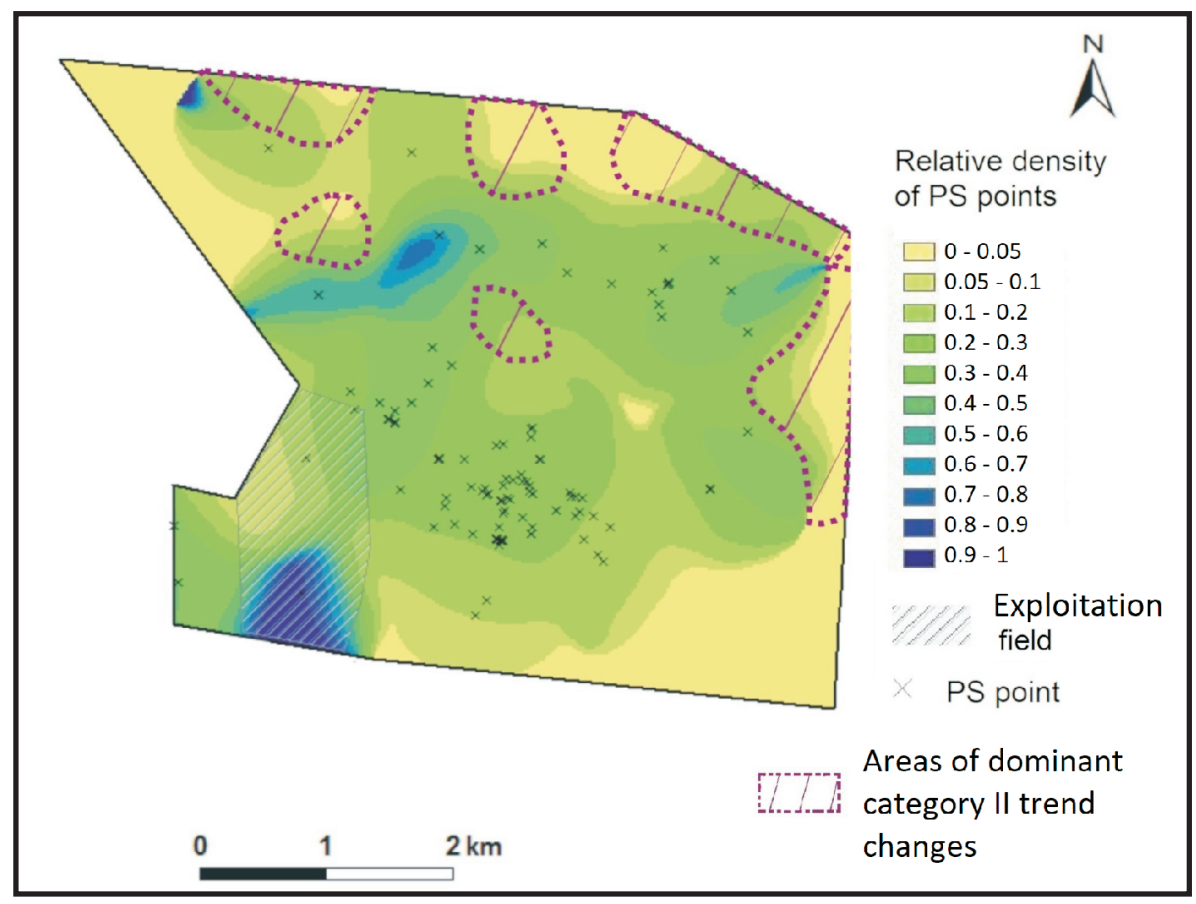

Fig. 19. The relative density of PS points for which trend changes occurred between III.1999 and IV.2000 (category II)

the area located near the exploitation field. It should be pointed out that coal exploitation in this mine came to an end in December 1998.

\section{DISCUSSION}

The present study demonstrated that slow, long-term ground deformations are a characteristic feature of the Dabrowa Basin area. Spatial analysis of these deformation values revealed the presence of a regional trend. Regular changes in deformation values were detected in a SW-NE direction (perpendicular to the Będziński Fault line). Subsidence is typical for the downthrown block of the Będziński Fault. The highest subsidence rate values were detected near the fault line. The deformation velocity values decline to zero in the upthrown block of the Będziński Fault. Such a pattern may indicate the occurrence of neotectonic movements along the fault plane. The analysis of short-range variation performed in this study revealed the presence of areas with high subsidence rates in the downthrown block of the fault. These deformations, which were not identified by regional trend analysis and are characterized by spatial autocorrelation, may be caused by coal exploitation.

As was revealed in a preliminary analysis described in Porzycka et al. (2010), a spatiotemporal analysis of ground deformation values revealed trend changes in $41 \%$ of all PS points. The authors found that PS points characterized by trend changes belonging to particular categories are not equally distributed in time and space. The analysis revealed that $38 \%$ of these trend changes occurred between X.93 and XII.95. Eighty percent of the changes involved an increase in subsidence velocities. Most of the trend changes occurred be- tween III.1999 and IV.2000, $75 \%$ of which were the changes that involved a decrease in subsidence velocity. Spatial analysis of PS point density was performed for those points where trend changes belonging to particular categories were discovered. It showed some regularity in density changes during particular time intervals. The analysis of PS point density values for the periods X.93-XI.94, XI.94-XII.95 and III.1999-IV.2000 showed that these values are generally oriented in a direction parallel to the Będziński Fault line.

\section{CONCLUSIONS}

The spatiotemporal analysis performed for the mining area of the "Grodziec" coal mine revealed a correlation between subsidence velocity and mining activity. The observed correlation is too distinctive to be treated as accidental. However, further analysis incorporating much more detailed information about coal exploitation is required.

The use of appropriate PSInSAR data analysis methods can help assess the impact of various factors on ground movement. The main factor affecting slow, long-term ground deformation values in the Dabrowa Basin is the neotectonic activity of this region. However, the impact of an additional factor, i.e. mining activity, has also been observed.

Acknowledgements. We would like to thank reviewers for their insightful comments on the paper. This work was financed by the AGH - University of Science and Technology, Faculty of Geology, Geophysics and Environmental Protection, Department of Geoinformatics and Applied Computer Science, as a part of statutory research. 


\section{REFERENCES}

Antonielli, B., Monserrat, O., Bonini, M., Cenni, N., Devanthéry, N., Righini, G., Sani, F., 2016. Persistent Scatterer Interferometry analysis of ground deformation in the Po Plain (PiacenzaReggio Emilia sector, Northern Italy): seismo-tectonic implications. Geophysical Journal International, 206: 1440-1455.

Ciepiela, B., 2003. Najstarsze i ostatnie kopalnie węgla kamiennego w Zagłębiu Dabrowskim (in Polish). Progres, Sosnowiec.

Crosetto, M., Monserrat, O., Cuevas-González, M., Devanthéry, N., Crippa, B., 2016. Persistent Scatterer Interferometry: a review. ISPRS Journal of Photogrammetry and Remote Sensing, 115: 78-89.

Declercq, P.Y., Devleeschouwer, X., Pouriel, C., 2005. Subsidence revealed by PSInSAR technique in the Ottignies-Wavre area (Belgium) related to water pumping in urban area. Proceedings of FRINGE 2005 Workshop, Frascati (Italy), 28 November-2 December.

DePrekel, K., Bouali, E.H., Oommen, T., 2018. Monitoring the impact of groundwater pumping on infrastructure using Geographic Information System (GIS) and Persistent Scatterer Interferometry (PSI). Infrastructures, 3: 57.

Ferretti, A., Prati, C., Rocca, F., 2000. Nonlinear subsidence rate using permanent scatterers in differential SAR interferometry. IEEE Transactions on Geoscience and Remote Sensing, 38: 2202-2212.

Ferretti, A., Prati, C., Rocca, F., 2001. Permanent scatterers in SAR interferometry. IEEE Transactions on Geoscience and Remote Sensing, 39: 8-20.

Ferretti, A., Bianchi, M., Novali, F., Tamburini, A., Rucci, A., 2008. Volcanic deformation mapping using PSInSAR ${ }^{T M}$ : Piton de la Fournaise, Stromboli and Vulcano test sites for Globvolcano project. IEEE Xplore.

Gehlot, S., Verbree, E., Hanssen, R.F., 2005. Dissemination of PS-InSAR results for improved interpretation and analysis. Proceedings of FRINGE 2005 Workshop, Frascati (Italy), 28 November-2 December.

Graniczny, M., Kowalski, Z., Jureczka, J., Czarnogórska, M., Piątkowska, A., 2008. Preliminary interpretation of PSI data of the northeastern part of Upper Silesian Coal Basin (Sosnowiec test site) - TerraFirma project. Polish Geological Institute Special Papers, 24: 29-36.
Huang, C., Xia, H., Hu, J., 2019. Surface deformation monitoring in coal mine area based on PSI. IEEE Access, 7: 29672-29678.

Ishitsuka, K., Prats-Iraola, P., Nannini, M., 2015. ALOS/PALSAR and TerraSAR-X persistent scatterer interferometry around Tokyo: interferometric phase evaluation and validation. IEEE International Geoscience and Remote Sensing Symposium (IGARSS), Milan: 1421-1424.

Lagios, E., Papadimitriou, P., Novali, F., Sakkas, V., Fumagalli, A., Vlachou, K., Del Conte, S., 2012. Combined Seismicity Pattern Analysis, DGPS and PSInSAR studies in the broader area of Cephalonia (Greece). Tectonophysics, 524-525: 43-58.

Leśniak, A., Porzycka, S., 2009. Impact of tectonics on ground deformations caused by mining activity in the north-eastern part of the Upper Silesian Coal Basin. Mineral Resources Management, 25: 227-238.

Massironia, M., M., Zampieria, D., Bianchib, M., Schiavoc, A., Franceschinid, A., 2009. Use of PSInSAR ${ }^{\mathrm{TM}}$ data to infer active tectonics: clues on the differential uplift across the Giudicarie belt (Central-Eastern Alps, Italy). Tectonophysics, 476: 297-303.

Perski, Z., 1999. Surface subsidence of the Upper Silesian Coal Basin (Southern Poland) due to mining, data detected by satellite radar interferometry (in Polish with English summary). Przegląd Geologiczny, 47: 171-174.

Porzycka, S., Leśniak, A., 2010. Temporal analysis of slow ground deformations in the area of Dabrowa Basin (in Polish with English summary). Przegląd Górniczy, 66: 70-75.

Rizzo, M.L., 2007. Statistical Computing with R. Chapman and Hall/CRC. Taylor and Francis Group.

Sen, A., Srivastava, M., 1990. Regression Analysis. Theory, Methods, and Applications. Springer, New York.

Silverman, B.W., 1986. Density Estimation for Statistics and Data Analysis. Chapman and Hall, London.

Trzepierczyński, J. eds., 1985. Tektonika Górnośląskiego Zagłębia Węglowego (in Polish). Wydawnictwo Uniwersytetu Śląskiego, Katowice.

Walter, L.A., Gotway, C.A., 2004. Applied Spatial Statistics for Public Health Data. John Wiley and Sons, New Jersey.

Weckernagel, H., 1995. Multivariate Geostatistics. Springer, Heidelberg. 